\title{
RESEARCH
}

Open Access

\section{Platelet-rich plasma injection versus surgical and medical treatment of mild- moderate carpal tunnel syndrome}

\author{
MA Eltabl, DS Saif* (D) and SE Alemam
}

\begin{abstract}
Carpal tunnel syndrome (CTS) accounts for approximately 90\% of peripheral entrapment neuropathy cases. Treatments of CTS as splinting, corticosteroid injection, and surgery are not 100\% effective, and alternative treatments are worth exploring. Surgery indicated in patients with persistent numbness, pain, and motor dysfunction. Empirical evidence indicates that many patients with CTS respond to anti-inflammatory medications. Recently, major attention has been drawn to platelet-rich plasma (PRP) for its possible effects on axon regeneration and neurological recovery.

Objectives: To evaluate the therapeutic efficacy of single ultrasound guided PRP injection of CTS versus surgical procedures and medical treatment in patients with mild-moderate CTS regarding pain relief and function improvement.
\end{abstract}

Methods: Thirty patients were injected in the carpal tunnel with single ultrasound-guided PRP (1-2 ml) injections; 30 patients went to surgical procedure, and 30 patients received conventional medical treatment and hand support. They were followed by using VAS (visual analogue scale), Boston questionnaire for CTS, and nerve conduction study for clinical improvement.

Results: Both groups of patients who had received PRP injection and who underwent to surgery showed improvements in their scores of evaluation parameters at 6 months post intervention, while the third group that received medical treatment shows insignificant improvement at 6 months post treatment.

Conclusion: PRP can be considered as a safe, less invasive, and long-lasting alternative to surgery and effective with one shot session compared to medical treatment in management of mild-moderate CTS.

Trial registration: Clinical trial.govID: NCT04235426.

Unique protocol ID:1472.

Verification date: January 2020.

Keywords: PRP, Carpal tunnel syndrome, Nerve conduction study, VAS, Injection medical treatment

\footnotetext{
*Correspondence: Sdalia30@gmail.com

Faculty of medicine, Menoufia University, Shebeen el kom, Egypt
}

(c) The Author(s). 2020 Open Access This article is licensed under a Creative Commons Attribution 4.0 International License, which permits use, sharing, adaptation, distribution and reproduction in any medium or format, as long as you give appropriate credit to the original author(s) and the source, provide a link to the Creative Commons licence, and indicate if changes were made. The images or other third party material in this article are included in the article's Creative Commons licence, unless indicated otherwise in a credit line to the material. If material is not included in the article's Creative Commons licence and your intended use is not permitted by statutory regulation or exceeds the permitted use, you will need to obtain permission directly from the copyright holder. To view a copy of this licence, visit http://creativecommons.org/licenses/by/4.0/. 


\section{Introduction}

Carpal tunnel syndrome (CTS) accounts for approximately $90 \%$ of peripheral entrapment neuropathy cases [1]. Existing evidence-based treatments for carpal tunnel syndrome, splinting, corticosteroid injection, and surgery are not $100 \%$ effective, and alternative treatments are worth exploring $[2,3]$. Surgery indicated in patients with persistent numbness and pain, motor dysfunction with diminished grip or pinch grasping, or thenar eminence flattening [4].

Empirical evidence indicates that many patients with CTS have self-limiting symptoms and respond to nonoperative conservative treatments, including rest, modification of physical behaviors, splinting, nerve-gliding exercises, manual therapy techniques, and anti-inflammatory medications [5].

Platelet-rich plasma (PRP) is a biological product of condensed platelet that contains multiple growth factors and has anti-inflammatory and regenerating effect with subsequently positive impacts on neuronal healing and axon regeneration [6-8].

We aim in this study to evaluate the therapeutic efficacy of single ultrasound-guided platelet-rich plasma injection of the carpal tunnel versus surgical procedures and medical treatment and hand support in patients with mildmoderate carpal tunnel regarding pain relief and function improvement during a follow-up period of 6 months.

\section{Material and methods}

Ninety patients aged between 20 and 60 years were collected in the period from January 2018 to January 2019 from outpatient clinic of neurosurgery and physical medicine, rheumatology, and rehabilitation department at Menoufia University Hospitals with signs and symptoms of CTS, and a confirmed diagnosis of moderate CTS based on history (paresthesia or dysesthesia and painful swelling of the hand with clumsiness due to weakness that is exacerbated by repetitive use or sleep and improved by shaking the hand), physical examination (sensory loss and numbness in the areas of the hand, innervated by the median nerve $(\mathrm{MN})$, positive Phalen's test, and/or Tinel's test), and electrophysiological studies was included. The severity of CTS was determined according to the electrophysiological classification proposed by Stevens et al. [9]. Mild CTS was defined as sensory latency of longer than $3.6 \mathrm{~ms}$ with or without reduced amplitude of sensory nerve action potential; moderate CTS was defined as sensory latency of longer than $3.6 \mathrm{~ms}$ plus a prolonged motor latency (4.3$6 \mathrm{~ms}$ ) with normal motor amplitude, so we selected for the present study mild-moderate CTS patients with sensory latency of longer than $3.6 \mathrm{~ms}$ plus a prolonged motor latency $(4.3-6 \mathrm{~ms})$ with normal motor and sensory amplitude. All patients were from the Menoufia Governorate. The research protocol was approved by ethical committee in Faculty of Medicine, Menoufia University. An informed written consent was obtained from each patient.

The presenting study excludes pregnancy, history of underlying metabolic diseases (such as diabetes mellitus, thyroid diseases, rheumatoid arthritis), history of local corticosteroid injection in the past 3 months, atrophy of thenar muscles, previous carpal tunnel release surgery, and evidence of concomitant neuropathy or radiculopathy. Patients with PRP contraindications including history of malignancies, autoimmune or hematologic disorders, and non-

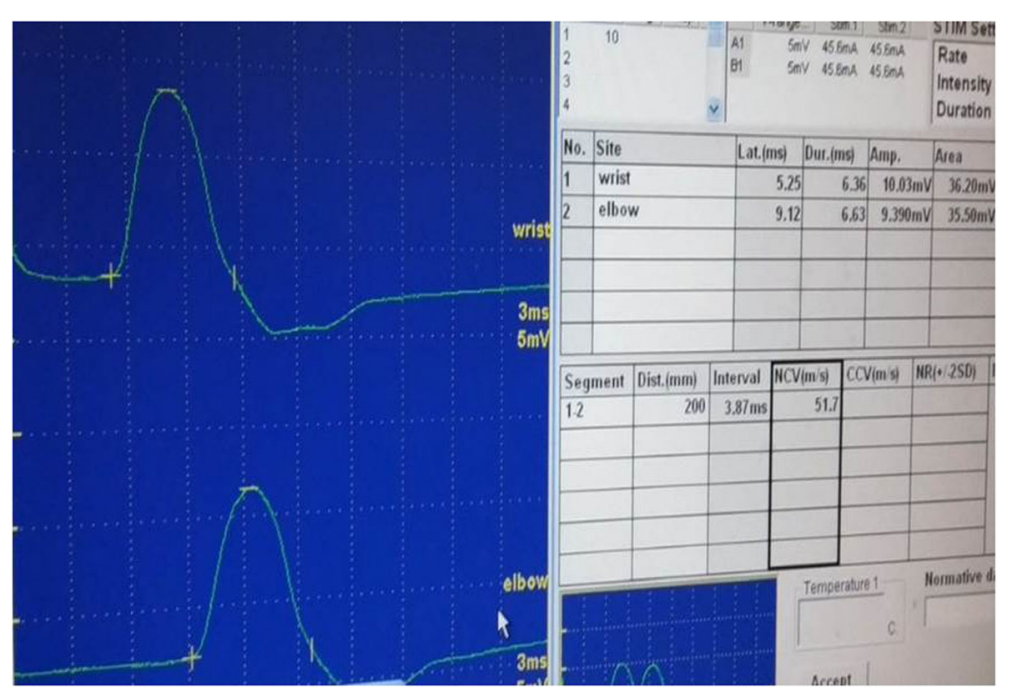

Fig. 1 MNCS of patient of the first group before injection with delayed distal motor latency, normal amplitude, and conduction velocity 


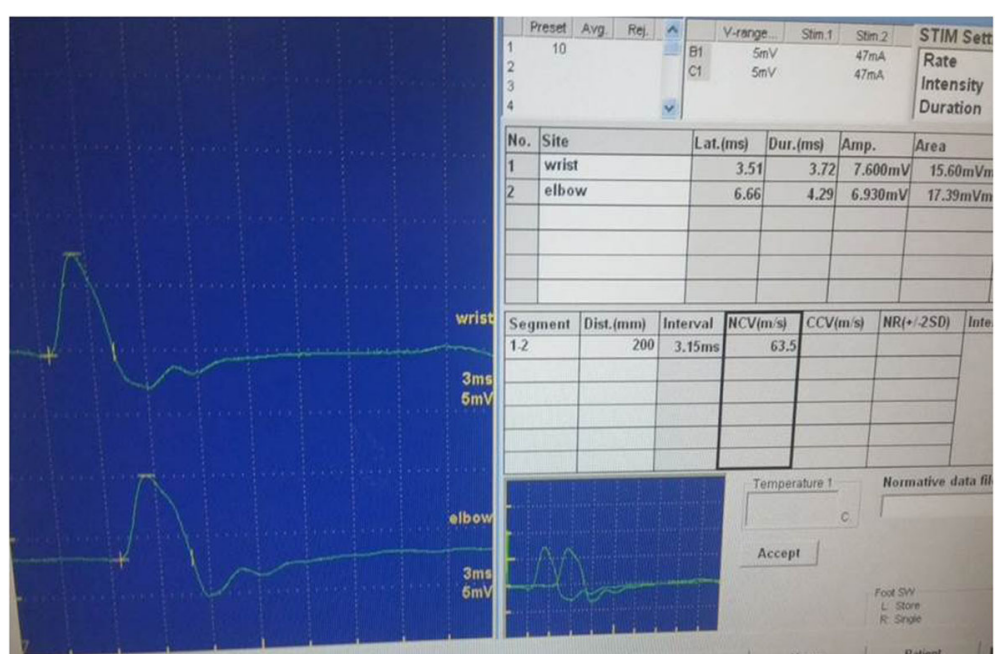

Fig. 2 MNCS of patient of the first group after injection with normal parameters. Motor conductive study of median nerve at 6 months post PRP injection with normal parameters (latency, amplitude, and conduction velocity)

steroidal anti-inflammatory drugs (NSAID) consumption 2 days prior to injection, treatment with anti-platelet and anticoagulant agents, Hb level under $12 \mathrm{~g} / \mathrm{dl}$, and platelet count under 150,000 in milliliter were also excluded.

All patients were subjected to demographic data recording, history taking, and clinical examination including general examination and local examination of the hand, and all have done complete blood count $(\mathrm{CBC})$, erythrocyte sedimentation rate (ESR), c-reactive protein $(\mathrm{CRP})$, hepatitis $\mathrm{C}$ virus antibody $(\mathrm{HCV})$, and serum uric acid by ELISA. The pain severity was determined by the patients, on a scale of 0 (no pain) to 10 (agonizing pain) according to the VAS $[10,11]$.

Electrophysiological parameters before and after intervention including the peak latency (PL) and the onset latency (OL) of sensory nerve action potential (SNAP) and distal motor latency of the compound muscle action potential (CMAP) were measured for all patients using a NIHON KOHDEN apparatus for electrophysiological

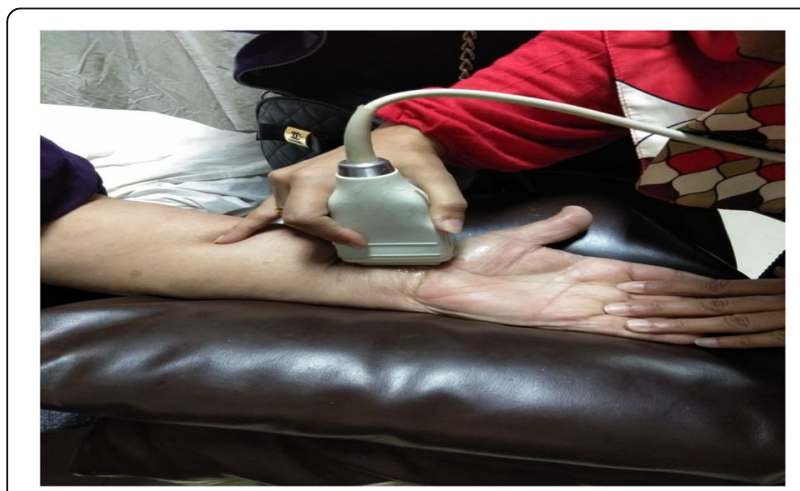

Fig. 3 Ultrasound probe on the medial aspect of wrist at the median nerve study (nerve conduction study and electromyography) Launches Neuropack ${ }^{\circ}$ S3 Electrodiagnostic System Offering Unparalleled Clean Waveforms Multimodality Diagnostic Platform Designed to Streamline Workflow for Better Clinical Care (Figs. 1 and 2).

Patient evaluation before and after intervention by clinical interaction by means of the Italian version of the Boston Carpal Tunnel Questionnaire (BCTQ). This is a validated questionnaire with two scales: symptoms (SYMP) and function (FUNC). The scores range from 1 to 5 points, with 1 indicating best health and 5 representing worst health [12].

Patients of the study group were divided into three groups as they were randomized to receive PRP or medical treatment or went to surgery in an equal ratio using a computer-generated code: Thirty patients were injected single ultrasound-guided PRP in the carpal tunnel (Figs. 3, 4 and 5); thirty patients went to surgical procedure, and thirty patients received medical treatment and hand support.

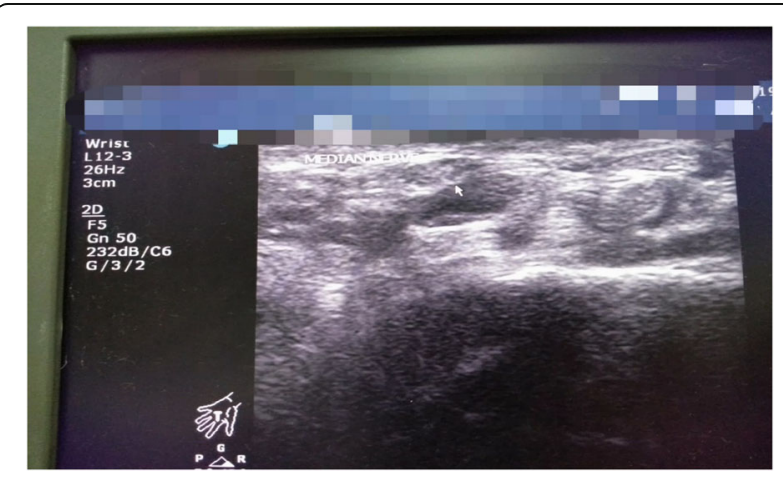

Fig. 4 Ultrasound image shows basiform bone and scaphoid bone, and the arrow shows the median nerve 


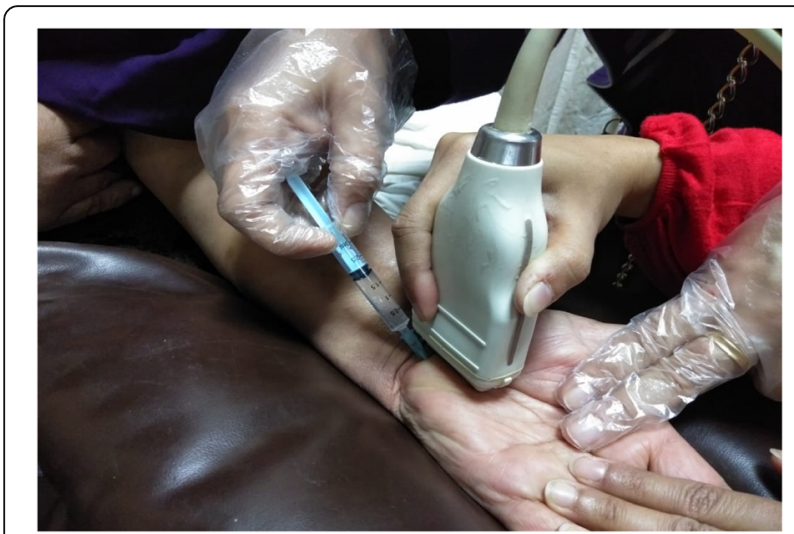

Fig. 5 The needle is inserted $1 \mathrm{~cm}$ medially to palmaris longus tendon with ultrasound probe on the injected point

Platelet-rich plasma prepared by taken $10 \mathrm{ml}$ of venous blood sample from every patient and was collected in sterile sodium citrated tubes. Then, the tubes with citrated blood were centrifuged at $3500 \mathrm{rpm}$ (revolutions per minute) for 9 min to separate erythrocytes and produce about 1-2 $\mathrm{ml}$ of PRP for injection [13].

The data collected were tabulated and analyzed by SPSS (statistical package for the social science software) statistical package version 16 on IBM compatible computer [14].

\section{Results}

Patients of the present study divided into 3 groups; the first group included 30 patients with mild-moderate CTS, and they received single ultrasound-guided PRP (1-2 ml) injection treatments to the carpal tunnel. The second group included 30 patients with mild-moderate CTS went to surgical procedure, and the third group of patients with mild-moderate CTS received medical treatment and hand support. They were evaluated at a baseline and at 6 months post intervention with comparing the results of all groups regarding improvement of pain, symptoms severity scale, functional state, visual analogue scale (VAS), Boston Carpal Tunnel Questionnaire (BCTQ), and the electrophysiological results.
There was insignificant difference in the patients of the three study groups regarding age and sex as in Table 1.

Our study revealed a significant improvement of pain at 6 months post-injection in the 30 patients who underwent autologous PRP injection compared to the baseline, as VAS score was $(8.53 \pm 1.04)$ at baseline before injection, and it showed improvement at 6 months $(1.97 \pm$ 0.72 ) as in Table 2.

There was a significant improvement of median nerve peak sensory latency post-injection as it was $5.10 \pm 0.96$ at baseline, and at 6 months post-injection became $2.95 \pm$ 0.56 and median nerve distal motor latency as it was before injection $(5.47 \pm 0.58)$, and at 6 months post-injection became $3.86 \pm 0.37$ as in Table 2 .

At the end of 6 months, post-injection symptoms severity scale was $1.0 \pm 0.0$ compared to baseline parameters that was $3.17 \pm 0.38$; also, functional state at the end of 6 months post-injection was $1.4 \pm 0.03$ compared to the baseline parameters that was $2.93 \pm 0.22$ in the $1^{\text {st }}$ group, so there was a significant improvement of symptoms severity scale and functional state at 6 months post-injection in the 1st group of patients regarding Boston Carpal Tunnel Questionnaire (BCTQ) as in Table 2.

There was a significant improvement of visual analogue scale after surgery as it was $8.03 \pm 1.2$, while at 6 months post-operation it became $2.4 \pm 0.85$ in the $2^{\text {nd }}$ group of patients who went to surgery as in Table 3 . There was significant improvement of median nerve peak sensory latency and distal motor latency at 6 months post-operation compared to baseline as $\mathrm{p}$ value was 0.001 as in Table 3.

There was a gradual improvement of symptoms severity scale at 6 months post-operation as it was $1.0 \pm 0.0$ compared to the baseline parameters which was $3.17 \pm$ 0.38 , and gradual improvement of the functional state at 6 months post-operation as it was $1.07 \pm 0.05$ compared to the baseline parameter which was $2.96 \pm 0.33$ in the 2nd group as in Table 3.

There was a significant improvement of pain regarding visual analogue scale at 6 months post medical treatment and hand support in the 3rd group of patients as in Table 4.

Table 1 Demographic data among patients of the three groups

\begin{tabular}{|c|c|c|c|c|c|c|c|c|}
\hline & \multicolumn{2}{|c|}{$\begin{array}{l}\text { Group } 1 \text { (PRP) } \\
M \pm S D\end{array}$} & \multicolumn{2}{|c|}{$\begin{array}{l}\text { Group 2s (Surg) } \\
M \pm S D\end{array}$} & \multicolumn{2}{|c|}{$\begin{array}{l}\text { Group } 3 \text { (Med) } \\
M \pm S D\end{array}$} & F-Test & P-Value \\
\hline Age & \multicolumn{2}{|c|}{$37.93 \pm 7.40$} & \multicolumn{2}{|c|}{$39.80 \pm 7.39$} & \multicolumn{2}{|c|}{$39.80 \pm 7.39$} & 0.141 & 0.708 \\
\hline Sex & No. & $\%$ & No. & $\%$ & No. & $\%$ & $\times 2$ & \\
\hline$\triangleright$ Male & 11 & $36.7 \%$ & 12 & $40 \%$ & 13 & $43.3 \%$ & P 278 & 08 \\
\hline$\Delta$ Female & 19 & $63.3 \%$ & 18 & $60 \%$ & 17 & $56.7 \%$ & 0.278 & $0.8 / 0$ \\
\hline
\end{tabular}

This table shows insignificant differences between the three groups regarding age and sex

$M$ mean, SD standard deviation, \% percentage, No. number, PRP platelet rich plasma injected group. Surg = group went to surgery. Med = group received medical treatment 
Table 2 Visual analogue scale, Boston questionnaire of CTS and electrophysiological parameters of median nerve in the first group of patients at 6 months post-injection compared to baseline parameters

\begin{tabular}{lllll}
\hline Group 1 & $\begin{array}{l}\text { baseline } 0 \\
\mathrm{M} \pm \mathrm{SD}\end{array}$ & $\begin{array}{l}6 \text { months post-injection } \\
\mathrm{M} \pm \mathrm{SD}\end{array}$ & T-Test & \multicolumn{2}{c}{-Value } \\
\hline VAS & $8.53 \pm 1.04$ & $1.97 \pm 0.72$ & 40.07 & 0.001 \\
Symptoms severity & $3.17 \pm 0.38$ & $1.0 \pm 0.0$ & 31.3 & 0.001 \\
Functional state & $2.93 \pm 0.22$ & $1.4 \pm 0.03$ & 1.92 & 0.001 \\
Distal motor latency & $5.47 \pm 0.58$ & $3.86 \pm 0.379$ & 16.6 & 0.001 \\
Peak sensory latency & $5.1 \pm 0.96$ & $2.95 \pm 0.56$ & 19.8 & 0.001 \\
\hline
\end{tabular}

There is significant improvement of pain, function, and electrophysiological parameters regarding median peak sensory and distal motor latency at 6 months post-injection

$M$ mean, $S D$ standard deviation, VAS visual analogue scale

There was insignificant improvement of median nerve peak sensory latency and distal motor latency, symptoms severity scale, and functional state at 6 months postmedical treatments compared to baseline as in Table 4.

There were insignificant differences between the three groups before intervention and significant statically differences of pain and function and electrophysiological parameters at 6 months post intervention by comparing both first and second groups with the third group while the first and second groups were comparable Table 5.

\section{Discussion}

Our study evaluates the role of platelet-rich plasma injection in patients with mild-moderate carpal tunnel syndrome compared to surgical and medical procedure; we recruited a large sample of patients and rely on a longer period of follow-up (6 months), and the injection was ultrasound guided not blind that provide accurate findings compared to other similar studies; our results rely on an subjective and objective methods of assessment as electrophysiological study regarding motor and sensory conductive study for more accurate findings.

Our study revealed a significant improvement of pain and function at 6 months post-injection of platelet-rich plasma in the 1st and post-surgery in the 2nd group of patients compared to the baseline regarding VAS and Boston questionnaire of CTS.
In agreement to our results, Malahias et al. and Yung-Tsan et al. $[15,16]$ and their colleague reported a significant improvement of pain regarding VAS and function regarding QDASH (quick Disabilities of the Arm, Shoulder and Hand) score in patients with mild-moderate carpal tunnel syndrome who received single-dose injection of PRP and throughout 3 months of follow-up post-injection compared to baseline parameters.

There was a significant improvement of median nerve peak sensory latency and distal motor latency at 6 months post-injection compared to the baseline in the 1st and 2nd groups of patients compared to their baseline parameters.

This comes in agreement with Yung-Tsan et al. [16] and Zheng et al. [4] and their teams as they revealed a similar results, and they reported the gradual sustained improvement of electrophysiological parameters regarding median nerve peak sensory latency and distal motor latency in patients with mild-moderate CTS at 6 months post-injection with platelet-rich plasma and explain that by the role of PRP in facilitation of Schwann cell proliferation, production of neurotrophic, and nerve growth factors with subsequent improvement of nerve electrophysiological parameters.

In accordance to our results, Piskin et al. [17] reported that PRP has not a role in axonal regeneration of peripheral nerve healing, and its role limited to regeneration of

Table 3 Visual analogue scale, Boston questionnaire of CTS and electrophysiological parameters of median nerve in the second group of patients at 6 months post-surgery compared to baseline parameters

\begin{tabular}{lllll}
\hline Group 2 & baseline 0 & 6 months post-injection & T-Test & \\
\hline VAS & $\mathrm{M} \pm$ SD & $2.0 \mathrm{SD}$ & 45.46 & 0.001 \\
Symptoms severity & $8.03 \pm 1.2$ & $2.4 \pm 0.85$ & 31.3 & 0.001 \\
Functional state & $3.17 \pm 0.38$ & $1.0 \pm 0.0$ & 1.87 & 0.001 \\
Median motor latency & $2.96 \pm 0.33$ & $1.07 \pm 0.05$ & 40.75 & 0.001 \\
Median sensory latency & $5.6 \pm 0.49$ & $3.73 \pm 0.589$ & 21.63 & 0.001 \\
\hline
\end{tabular}

There is significant improvement of pain, function, and electrophysiological parameters regarding median peak sensory and distal motor latency at 6 months post-surgery

VAS visual analogue scale, $M$ mean, $S D$ standard deviation 
Table 4 Visual analogue scale, Boston questionnaire of CTS and electrophysiological parameters of median nerve in the third group of patients at 6 months post-medication compared to baseline parameters

\begin{tabular}{lllll}
\hline Group 3 & $\begin{array}{l}\text { baseline } 0 \\
\mathrm{M} \pm \mathrm{SD}\end{array}$ & $\begin{array}{l}6 \text { months post-injection } \\
\mathrm{M} \pm \mathrm{SD}\end{array}$ & T-Test & \multicolumn{1}{c}{-Value } \\
\hline VAS & $8.0 \pm 1.125$ & $7.74 \pm 1.45$ & 1.97 & 0.058 \\
Symptoms severity & $3.23 \pm 0.43$ & $3.13 \pm 0.67$ & 1.14 & 0.264 \\
Functional state & $2.87 \pm 0.34$ & $2.81 \pm 0.46$ & 1.48 & 0.571 \\
Median motor latency & $5.41 \pm 0.49$ & $5.32 \pm 0.59$ & 0.721 & 0.477 \\
Median sensory latency & $5.52 \pm 0.87$ & $5.46 \pm 0.99$ & 1.79 & 0.083 \\
\hline
\end{tabular}

There is significant improvement of pain and insignificant improvement of function and electrophysiological parameters regarding median peak sensory and distal motor latency at 6 months post-medication

$M$ mean, $S D$ standard deviation, VAS visual analogue scale

Table 5 Visual analogue scale and Boston questionnaire of CTS and electrophysiological parameters among the three groups of patients at baseline and at 6 months post intervention

\begin{tabular}{|c|c|c|c|c|c|c|}
\hline$\overline{\text { Vas }}$ & $\begin{array}{l}\text { Group } 1 \\
\mathrm{M} \pm \mathrm{SD}\end{array}$ & $\begin{array}{l}\text { Group } 2 \\
\mathrm{M} \pm \mathrm{SD}\end{array}$ & $\begin{array}{l}\text { Group } 3 \\
\mathrm{M} \pm \mathrm{SD}\end{array}$ & F-Test & $\boldsymbol{P}$-Value & LSD \\
\hline & & & & & & $P 1=0.09$ \\
\hline \multirow[t]{3}{*}{ VAS 0} & $8.53 \pm 1.04$ & $8.03 \pm 1.2$ & $8.0 \pm 1.125$ & 2.110 & 0.127 & $P 2=0.069$ \\
\hline & & & & & & P3 $=0.909$ \\
\hline & $1.97 \pm 0.72$ & $2.4 \pm 0.85$ & $7.74 \pm 1.45$ & 276.908 & 0.001 & $P 1=0.094$ \\
\hline \multirow[t]{3}{*}{ VAS 6} & & & & & & $P 2=0.01$ \\
\hline & & & & & & P3 $=0.01$ \\
\hline & & & $3.23 \pm 0.43$ & & & $\mathrm{P} 1=1.0$ \\
\hline \multirow[t]{3}{*}{ Symptoms severity 0} & $3.17 \pm 0.38$ & $3.17 \pm 0.38$ & & 0.229 & 0.796 & $\mathrm{P} 2=0.561$ \\
\hline & & & & & & $\mathrm{P} 3=0.561$ \\
\hline & & & $3.13 \pm 0.67$ & & & $\mathrm{P} 1=1.0$ \\
\hline \multirow[t]{3}{*}{ Symptoms severity 6} & $1.0 \pm 0.0$ & $1.0 \pm 0.0$ & & 302.325 & 0.001 & $\mathrm{P} 2=0.001$ \\
\hline & & & & & & P3 $=0.001$ \\
\hline & & & $2.87 \pm 0.34$ & & & $\mathrm{P} 1=1.00$ \\
\hline \multirow[t]{3}{*}{ Functional state 0} & $2.93 \pm 0.22$ & $2.96 \pm 0.33$ & & 4.298 & 0.017 & $\mathrm{P} 2=0.013$ \\
\hline & & & & & & P3 $=0.013$ \\
\hline & & & $2.81 \pm 0.46$ & & & $\mathrm{P} 1=1.0$ \\
\hline \multirow[t]{3}{*}{ Functional state 6} & $1.4 \pm 0.03$ & $1.07 \pm 0.05$ & & 411.575 & 0.001 & $P 2=0.001$ \\
\hline & & & & & & P3 $=0.001$ \\
\hline & & & $5.52 \pm 0.87$ & & & $P 1=0.532$ \\
\hline \multirow[t]{3}{*}{ Peak sensory latency 0} & $5.1 \pm 0.96$ & $5.24 \pm 0.885$ & & 1.661 & 0.196 & $P 2=0.076$ \\
\hline & & & & & & $\mathrm{P3}=0.248$ \\
\hline & & & $5.46 \pm 0.99$ & & & $P 1=0.876$ \\
\hline \multirow[t]{3}{*}{ Peak sensory latency 6} & $2.95 \pm 0.56$ & $2.93 \pm 0.56$ & & 118.144 & 0.001 & $\mathrm{P} 2=0.001$ \\
\hline & & & & & & P3 $=0.001$ \\
\hline & & & $5.41 \pm 0.49$ & & & $P 1=0.354$ \\
\hline \multirow[t]{3}{*}{ Distal motor latency 0} & $5.47 \pm 0.58$ & $5.6 \pm 0.49$ & & 0.997 & 0.373 & $\mathrm{P} 2=0.655$ \\
\hline & & & & & & P3 $=0.169$ \\
\hline & & & $5.32 \pm 0.59$ & & & $P 1=0.333$ \\
\hline \multirow[t]{2}{*}{ Distal motor latency 6} & $3.86 \pm 0.379$ & $3.73 \pm 0.589$ & & 84.522 & 0.001 & $\mathrm{P} 2=0.001$ \\
\hline & & & & & & $P 3=0.001$ \\
\hline
\end{tabular}

There were insignificant differences between the three groups before intervention and significant statically differences of pain and function and electrophysiological parameters at 6 months post intervention by comparing both first and second groups with the third group while the first and second groups were comparable $L S D$ least significant difference $=$ mean, $S D$ standard deviation, $0=$ at baseline, $6=$ at 6 months post-intervention. VAS Visual Analogue Scale 
myelin sheath with subsequent improvement of demyelinating neuropathy regarding peak sensory latency and distal motor latency in electrophysiological study such as in cases of mild-moderate CTS.

Gerritsen et al. [18] reported the significant improvement of pain and function in patients with mildmoderate CTS after surgery and documented that the optimal way of management of moderate CTS is the standard open carpal tunnel release surgery OCTR that is preferred than other non-surgical lines of treatment regarding lower risk of complications and of added costs.

The present study revealed significant improvement of pain and insignificant improvement of function, median nerve peak sensory latency, and distal motor latency at 6 months post-medical treatment and hand support in the 3rd group of patients compared to the baseline regarding electrophysiological study and Boston questionnaire of CTS.

There was a significant statically improvement of function and electrophysiological parameters of the first and second groups of patients compared to the third group at 6 months post intervention regarding median nerve distal motor, peak sensory latency, symptoms severity index, and functional state of Boston questionnaire of CTS.

In agreement with our results, Uzun et al. [19] reported a significant improvement of pain and function regarding VAS and BCTQ in patients with mildmoderate CTS who receiving PRP injection at 3 months post-treatment compared with patient group receiving steroid injection and medical treatment.

In another line Piazzini et al. [20] reported the efficacy of local and oral steroids, splints, NSAIDs, and diuretic medications in pain relief and improvement of function in patients with mild-moderate CTS.

Finally, O'Connor et al. [21] Carlson et al. [22] reported that non-surgical maneuvers as oral treatment, casting, and steroid injection have short-term relief of CTS symptoms and improvement of function.

\section{Conclusion}

Platelet-rich plasma can be considered as a safe, less invasive, and long-lasting alternative to surgery and effective with one shot session compared to medical treatment and hand support in management of patients with mild-moderate carpal tunnel syndrome.

\section{Abbreviations}

PRP: Platelet-rich plasma; VAS: Visual analogue scale; Vs: Versus; CBC: Complete blood count; ESR: Erythrocyte sedimentation rate; CRP: Creactive protein; HCV: Hepatitis C virus antibody; ELISA: Enzyme Linked Immune Assay; CTS: Carpal Tunnel Syndrome; BCTQ: Boston Carpal Tunnel Questionnaire; SYMP: Symptoms; FUNC: Function; MNCS: Motor Nerve Conduction Study; SNCS: Sensory Nerve Conduction Study; NCS: Nerve Conduction Study; OCTR: Open carpal tunnel release; NSAID: Non-steroidal anti-inflammatory drugs; SD: Standard deviation; M: Mean; \%: Percentage;
No.: Number; 0: At baseline; 6: At 6 months post-injection; MSL: Median sensory latency; MML: Median motor latency; Sym sev: Symptoms severity; Fun stat: Functional state; PL: Peak latency; OL: Onset latency; Surg: Group went to surgery; Med: Group received medical treatment; PRP group: Platelet-rich plasma injected group; MN: Median nerve; Hb: Hemoglobin; SPSS: Statistical package for the social science software; IBM: International Business Machines; QDASH: quick Disabilities of the Arm, Shoulder and Hand score; 1st: First; 2nd: Second; 3rd: Third

\section{Acknowledgements}

Not applicable.

\section{Authors' contributions}

Mohamed Ahmed El Tabl contributed the following: concepts, design, definition of intellectual content, data acquisition, statistical analysis, manuscript review, and guarantor. Dalia Salah Saif contributed the following: literature search, clinical studies, experimental studies, statistical analysis, manuscript review, and guarantor. Saeed Esmaeel AL Emam contributed the following: clinical studies, experimental studies, data acquisition, and manuscript editing. The authors read and approved the final manuscript.

\section{Funding}

Not applicable.

\section{Availability of data and materials}

All data generated or analyzed during this study are included in this published article and its supplementary information files.

\section{Ethics approval and consent to participate}

The research protocol was approved by ethical committee in faculty of medicine Menoufia University in its monthly session dated August/2019 with a registration number 19719NEUS6 with Clinical trial.govID:NCT04235426.

An informed written consent was obtained from each patient.

\section{Consent for publication}

The consent for publication was obtained from all persons sharing in the study.

\section{Competing interests}

The authors declare that they have no competing interests in this article.

Received: 2 November 2019 Accepted: 25 May 2020

Published online: 24 August 2020

\section{References}

1. Ghasemi-rad M, Nosair E, Vegh A, Mohammadi A, Akkad A, Lesha E etal., Handy review of carpal tunnel syndrome: from anatomy to diagnosis and treatment. World J Radiol. 2014;6(6):284

2. O'Connor D, Marshall SC, Massy-Westropp N, Pitt V. Non-surgical treatment (other than steroid injection) for carpal tunnel syndrome. Cochrane Database Syst Rev. 2003:1:32-9.

3. Raeissadat SA, Rayegani SM, Rezaei S, Sedighipour L, Bahrami MH, Eliaspour D, et al. The effect of polarized polychromatic noncoherent light(bioptron) therapy on patients with carpal tunnel syndrome. J Lasers Med Sci. 2014:5(1):39-46.

4. Zhang X, Li Y, Wen S, Zhu H, Shao X. Yu Yet al. Carpal tunnel release with subneural reconstruction of the transverse carpal ligament compared with isolated open and endoscopic release. Bone Joint J. 2015;97-B:221.

5. Mohamed Fl, Hassan AA, Abdel-Magied RA, Wageh RN. Manual therapy intervention in the treatment of patients with carpal tunnel syndrome: median nerve mobilization versus medical treatment. Egypt Rheumatol Rehabil J. 2016;43(1):27-34.

6. Sundman EA, Cole BJ, Fortier LA. Growth factor and catabolic cytokine concentrations are influenced by the cellular composition of platelet-rich plasma. Am J Sports Med. 2011;39(10):2135-40.

7. Farrag TY, Lehar M, Verhaegen P, Carson KA, Byrne PJ. Effect of platelet rich plasma and fibrin sealant on facial nerve regeneration in a rat model. Laryngoscope. 2007;117(1):157-65.

8. Zheng C, Zhu Q, Liu X, Huang X, He C, Jiang L, et al. Effect of plateletrich plasma (PRP) concentration on proliferation, neurotrophic function and migration of Schwann cells in vitro. J Tissue Eng Regen Med. 2016;10(5):428-36. 
9. Stevens JC, Smith BE, Weaver AL, Bosch EP, Deen HG, Wilkens JA. Symptoms of 100 patients with electromyographically verified carpal tunnel syndrome. Muscle Nerve. 1999;22(10):1448-56.

10. Goldstone,Kelly D,Gammon.Visual analogue scale(VAS).JClin Nurse.2001;10: 697-706.

11. Guillemin D.P.A. F, Briançon V.J.S. Bias and precision in visual analogue scales: a randomized controlled trial. Am J Epidemiol. 1999.15;150:1117-27.

12. Padua R, Padua L, Romanini E, Aulisa L., Lupparell.S, Sanguti.'Jetti. Boston Carpal Tunnel Questionnaire: Italian version. It J Orthop Traumatol.1998; 24:121-129.

13. Ito.M,Inage.K,Orita.H.S,Kamoda,Yamashita,Kubota et al.Asia SpineJ.Efficacy of platelet-rich plasma for bone fusion in transforaminal lumbar interbody fusion.2018; 12(1): 112-118.

14. Levesque. SPSS programming and data management. A Guide for SPSS and SAS Users. 2007. Fourth Edition, SPSS Inc., Chicago, 3.

15. Malahias.M.A, Johnson. E.O, Babis G.C, and Nikolaou V.S. Single injection of platelet-rich plasma as a novel treatment of carpal tunnel syndrome. Neural Regen Res. 2015; 10(11): 1856-1859.

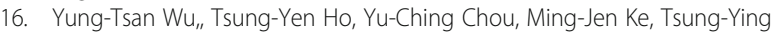
Li,Guo-Shu Huang, and Liang-Cheng Chen. Six-month efficacy of plateletrich plasma for carpal tunnel syndrome: a prospective randomized, singleblind controlled trial. Sci.Rep.J.2017;7:94.

17. Piskin A, Kaplan S, Aktaş A, Ayyildiz M, Raimondo S, Aliç T, et al. Platelet ge does not improve peripheral nerve regeneration: an electrophysiological, stereological, and electron microscopic study. Microsurgery. 2009;29:144-53.

18. Gerritsen AA, de Vet HC, Scholten RJ, van Tulder MW, Bouter LM. Enabling meta-analysis in systematic reviews on carpal tunnel syndrome. J.Hand Surg. Am. 2002;27:828-32.

19. Uzun H, Bitik O, Uzun Ö, Ersoy US, Aktaş E. Platelet-rich plasma versus corticosteroid injections for carpal tunnel syndrome. J Plast Surg Hand Surg. 2016;6:1-5.

20. Piazzini DB, Aprile I, Ferrara PE, Bertolini C, Tonali P, Maggi L, et al. A systematic review of conservative treatment of carpal tunnel syndrome. Clin. Rehabil. 2007;21:299-314.

21. O'Connor D, Marshall S, Massy-Westropp N. Non-surgical treatment (other than steroid injection) for carpal tunnel syndrome. Cochrane Database Syst. Rev. 2003:32:1-9.

22. Carlson H, Colbert A, Frydl J, Arnall E, Elliot M, Carlson N. Current options for nonsurgical management of carpal tunnel syndrome. Int J Clin Rheumtol. 2010;5(1):129-42.

\section{Publisher's Note}

Springer Nature remains neutral with regard to jurisdictional claims in published maps and institutional affiliations.

\section{Submit your manuscript to a SpringerOpen ${ }^{\circ}$ journal and benefit from:}

- Convenient online submission

- Rigorous peer review

- Open access: articles freely available online

High visibility within the field

- Retaining the copyright to your article

Submit your next manuscript at $\boldsymbol{\nabla}$ springeropen.com 